\title{
Assessment of the influence of jogging on the shape of female foot arches
}

\author{
Agata Maslon', Joanna Golec', Elzbieta Szczygiel², Dorota Czechowska', Boguslaw Golec ${ }^{1}$ \\ ${ }^{1}$ University of Physical Education in Cracow, Motor Rehabilitation Department, Clinical Rehabilitation Division, \\ Orthopedic Rehabilitation Institute, Cracow, Poland \\ ${ }_{2}^{2}$ Jagiellonian University Collegium Medicum, Health Science Division, Physiotherapy Institute Chair, Cracow, Poland
}

Maslon A, Golec J, Szczygiel E, Czechowska D, Golec B. Assessment of the influence of jogging on the shape of female foot arches. Ann Agric Environ Med. 2017; 24(4): 596-601. doi: 10.5604/12321966.1230672

\begin{abstract}
Introduction. Both walking and its faster, running, consist of cyclical subsequent phases of swing and support; however, they differ in their time proportions as well as magnitude of acting forces. There is a lack of studies concerning the longterm consequences of repeated jogging cycles on the function of feet and, above all, on their permanent impact on the shape of foot arches.

Objectives. The objective of this study was to answer the question whether regular jogging changes the shape of the transverse and medial longitudinal arches of the feet.

Materials and method. The research material consisted of 96 women with an average age of 26.57 , and included 50 actively jogging women, and 46 of non-joggers. The study was performed with the use of EMED-SF force platform. The plantar surface of the foot was divided into 10 regions according to Cavanagh, for which peak pressure and contact time were established. Two indicators were defined: metatarsal bone pressure distribution pattern acc. to Kantali, and longitudinal arch index acc. to Cavanagh.

Results. The data obtained revealed more frequent occurrence of the greatest pressure under the centrally located metatarsal heads (lack of functional foot transverse arch) among the female joggers, compared with the non-joggers. Moreover, the findings indicate the higher frequency of medial longitudinal foot arch flattening among female runners, with a great deal of consistency between both feet, whereas results for the control group show asymmetrical medial arch shapes with right foot propensity to normal arch shape and left foot tendency for excessive arch.

Conclusion. The observed differences in feet arch shapes between female joggers and non-joggers indicate the influence of jogging on feet functional adaptations.
\end{abstract}

\section{Key words}

foot medial arch, foot transverse arch, running biomechanics, women

\section{INTRODUCTION}

In order to obtain the efficient pressure absorption and distribution, as well as to improve and accelerate locomotion, the human foot is equipped with supporting arches. According to Kapandji, the foot functions as a tripod with three support areas, namely: the heel, the first and the fifth metatarsal bone, forming three arches: transverse, longitudinal lateral and longitudinal medial [1]. However, the presence of the transverse arch has been always controversial. Indeed, a number of studies prove that not the heads of the first and the fifth metatarsal bones, but instead the second, third and fourth which, according to the theory assuming the existence of a transverse arch and forming its peak, are under the greatest pressure [2]. The actual existence of a foot transverse arch is an important matter for discussion, as detailed knowledge of its anatomy would enable clinicians to make proper decisions about its malfunctions and subsequent treatment.

It is believed that the medial arch is the most valuable due to its functionality. It facilitates dispersing the majority of forces caused by body weight before they can be transferred

Address for correspondence: Agata Maslon, University of Physical Education in Cracow, Motor Rehabilitation Department, Clinical Rehabilitation Division, Orthopedic Rehabilitation Institute, AI. Jana Pawla II 78, 31-571 Krakow

E-mail:agata_maslon@yahoo.com

Received: 11 October 2013; accepted: 27 June 2014; first published on December, 2016 to the lower extremity upper segments [3]. Improper functioning of the medial arch allows the forces from the ground to be transferred proximally, without the medial arch 'filter'. In turn, this affects the muscles, talocrural, knee and pelvic joints and lumbosacral spine section [3]. The properly functioning longitudinal arch works in a similar way to a spring, gaining the energy during the contraction phase and then releasing part of it in the push-off phase. Therefore, dysfunction of the medial arch worsens dynamism and energy usage during the walking or running gait [4].

Walking and its faster form, running, are typical modes of locomotion for human and other primates. Both walking and running consist of cyclical subsequent phases of swing and support [5]. However, during running, the stance phase of the gait shortens from about $60 \%$ of the gait cycle to as little as $30 \%$. This considerably reduced stance phase causes increased demands on the foot, as it must change rapidly from a rigid structure at the initial contact with the ground to prevent buckling of the knee, to the planted foot which needs to be flexible enough to adjust to the surface and allow dispersing of the forces [6]. It is interesting whether this specific training and greater demands on the foot cause adjustments in its arch-shaped structure.

The available literature contains exhaustive information about changes in the feet loading pattern immediately after a running workout. However, there is a lack of studies concerning the long-term consequences of repeated jogging 
cycles on feet function and, above all, on their permanent impact on the shape of foot arches. The dynamics of changes in female joggers organisms are particularly interesting because, according to Taunton et al., women are considerably more vulnerable to feet structure transformations and related motor organs injuries [7]. Ferber et al., among the others, imply that this fact is a consequence of the clear differences between male and female lower extremities structure, different biomechanics of walking and running, as well as hormonal fluctuation related to the menstrual cycle [8].

\section{OBJECTIVE}

The objective of the study was to answer the following question: 'Does regular jogging change the foot function, namely: the shape of the transverse and medial longitudinal arches of the feet?'

\section{MATERIALS AND METHOD}

The research consisted of 96 women: a research group of 50 joggers and a control group of 46 women, who were neither active in jogging nor in any other forms of sports activity. The following inclusion criteria were established for both the research and control groups: age between 20-50, lack of acute injuries of the talocrural joint and feet, fractures of bones of the feet, and absence of deformations of the feet, such as bunion or hammer toes; healthy weight range, i.e. Body Mass Index (BMI) not exceeding 25. Moreover, women included in research group had to meet the criteria of jogging activity for at least 1 year and up to 10 years, and a weekly run mileages between $15-100 \mathrm{~km}$. All participants signed an individual Project Participation Consent Form.

The research was been approved by the Cracow District Medical Chamber Bioethics Committee, Approval No. 18/LBL/OIL/2012 of 8 February 2012.

The research was performed on EMED-SF force platform (Novel, Munich, Germany), measuring $360 \mathrm{~mm} \times 190 \mathrm{~mm}$, with 2,736 built-in sensors, which means a distribution equal to 4 per each $\mathrm{cm}^{2}$. The sensors record the active forces (between 0-127 N) during the whole period of foot-ground contact, with a frequency of $50 \mathrm{~Hz}$. A computer recorded the fluctuations of forces acting on individual sensors in platformfoot contact in real time, and the signal is transferred from the sensors to the computer memory. For the purpose of this study, the above-mentioned platform was built-in into a $5 \mathrm{~m} \times 1 \mathrm{~m}$ track along $2 / 3$ of its length. This ensured that the platform was the same height as the track and they created one continuous surface. The experiment involved several, trial walks through the force platform in natural rhythm and velocity, in order to assess appropriate starting point, i.e. the one assuring full foot-platform contact every third step, regardless of the step length ('mid-gait technique') [9]. Having determined the starting point, three trials for each foot were performed. If any of the above-measurement conditions were not met, more trials were performed, and the two most similar results used for analysis. The picture obtained was divided into 10 masks according to Cavanagh [10] (Fig. 1). Two parameters were assessed for each mask: peak pressure $\left[\mathrm{N} / \mathrm{cm}^{2}\right]\left(\mathrm{P}_{\max }\right)$ and contact area [\%] (Ca). Two indicators were selected, i.e. Indicator 1: Kantali metatarsal

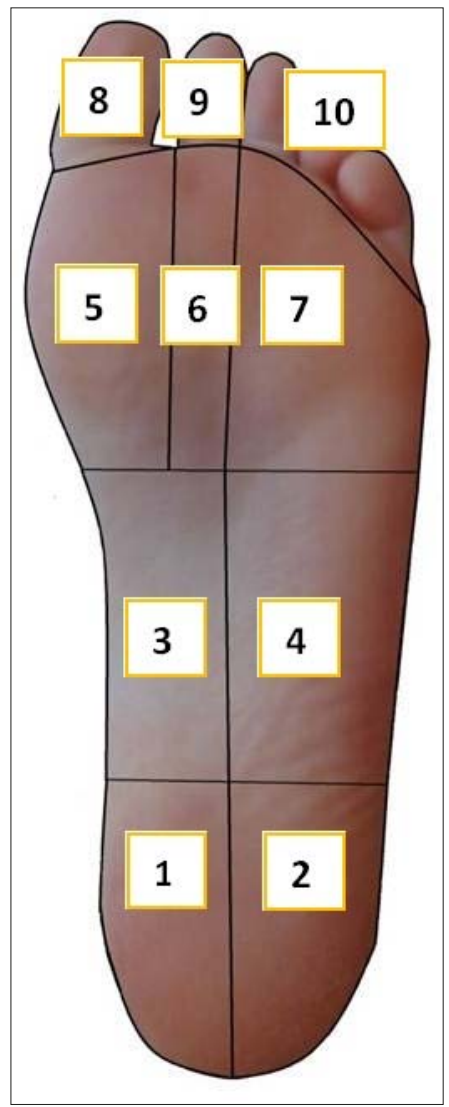

Figure 1. Division of foot sole into 10 regions according to Cavanagh [22]. (1) $\mathrm{MH}$ medial heel, (2) lateral heel (LH), (3) medial midfoot (MM), (4) lateral midfoot (LM), (5) first metatarsal head $\left(M_{1}\right),(6)$ second metatarsal head $\left(M_{2},(7)\right.$ third to fifth metatarsal head $\left(\mathrm{M}_{3}-\mathrm{M}_{5}\right)$, (8) hallux $(\mathrm{HX})$, (9) second toe $\left(T_{2}\right),(10)$ lateral toes $\left(T_{3-5}\right)$

bone pressure distribution pattern (arrangement of heads of metatarsal bones based on their maximum pressures on the ground) $M_{1}<M_{2}>M_{3-5}$ - the second metatarsal bone head subjected to the most intensive pressure, with lower pressure put on the remaining metatarsal bone heads, $\mathrm{M}_{1} \geq \mathrm{M}_{2}>\mathrm{M}_{3-5}{ }^{-}$ the greatest pressure found on the first metatarsal bone head, or equally, on the first and the second metatarsal bones, with lower pressure between the third and the fifth, $\mathrm{M}_{1}<\mathrm{M}_{2} \leq \mathrm{M}_{3-5^{-}}$ the greatest pressure put on metatarsal bones heads between the third and the fifth, or equally distributed between the third and the fifth, as well as the second metatarsal bones heads, $\mathrm{M}_{1}>\mathrm{M}_{2}<\mathrm{M}_{3-5}$ - the lowest pressure made on the second metatarsal bones head, with major pressure put on the remaining metatarsal bones heads (functional transverse arch) [11]; and Indicator 2: Longitudinal arch index according to Cavanagh (relation between full metatarsus (masks 3 and 4) contact surface and a sum of whole foot surface contact area, excluding toes (masks 1-7) (Fig. 1) [12]. To calculate AI the following equation was used:

$$
A I=\frac{3+4}{1+2+3+4+5+6+7} .
$$

Three groups were selected based on the distribution of AI results in the researched population:

(1 normal longitudinal medial arch $(13<\mathrm{AI}<24)$;

(2 flattened longitudinal medial arch $(\mathrm{AI} \geq 24)$;

(3 hollow foot (excessive longitudinal arch) $(\mathrm{AI} \leq 13)$. 
Statistical analysis. The research performed was completed with statistical analysis. Differences between the research and control groups (taking into consideration both left and right sides of the body) were verified regarding the distribution of variables with use of $t$ Student parametric test and U MannWhitney non-parametric test. The differences between right and left feet in the control and research groups were analyzed using $t$ Student test for the repeated data, Wilcoxon test (quantitative data) and $\mathrm{chi}^{2}$ independence test (qualitative data). The differences and relations established in the analysis were assessed as statistically significant if the p-value did not exceed 0.05 .

\section{RESULTS}

Most frequent metatarsal bone heads pressure pattern occurred metatarsal on bone heads in the right feet in the right feet in both the control and research groups was $\mathrm{M}_{1}<\mathrm{M}_{2}>\mathrm{M}_{3-5}$. It was observed more frequently in the jogging group than among the non-joggers (60\% and 50\% of participants, respectively). Less frequent patterns in both the control and research groups were: $\mathrm{M}_{1}<\mathrm{M}_{2} \leq \mathrm{M}_{3}-{ }_{5}$ (control group - 23.91\%, research group $-24 \%$ ) and $M_{1} \geq M_{2}>M_{3-5}$ (control group $-19.57 \%$, research group $-16 \%$ ). Finally, the $\mathrm{M}_{1}>\mathrm{M}_{2}<\mathrm{M}_{3}$. pattern was rarely noted in either group In the research group, none of the women had their forefoot areas loaded according to the $\mathrm{M}_{1}>\mathrm{M}_{2}<\mathrm{M}_{3}$ pattern, whereas in the control group this pattern was found in $6.52 \%$ of participants (Fig. 2).

In addition, for the left feet, the most frequent metatarsal bone heads pressure pattern was $\mathrm{M}_{1}<\mathrm{M}_{2}>\mathrm{M}_{3}-{ }_{5}$ in both groups, and occurred with approximately similar frequency (research group $-67.39 \%$, control group - 68\%). The differences, however, were observed for the incidences of $M_{1} \geq M_{2}>M_{3-5}$ and $M_{1}<M_{2} \leq M_{3-5}$ patterns. In the research group, the former pattern was confirmed for $26 \%$ of participants, whereas the latter was observed for only $6 \%$ of this group's participants. In the control group, these patterns frequency showed the opposite regularity: pattern $\mathrm{M}_{1} \geq \mathrm{M}_{2}>\mathrm{M}_{3-5}$ was found for $10.87 \%$ and $\mathrm{M}_{1}<\mathrm{M}_{2} \leq \mathrm{M}_{3}-{ }_{5}$ for $13.04 \%$ of the women. For both groups, the least frequent pattern was $\mathrm{M}_{1}>\mathrm{M}_{2}<\mathrm{M}_{3}-{ }_{5}$. In the research group, none of the included women had their feet loaded according to this pattern, whereas in the control group it was found in $8.7 \%$ of the participants (Fig. 2).

Statistically significant differences between the research group and the control group in the occurrence of Kantali metatarsal bone pressure distribution patterns were noted only for the left feet $(\mathrm{p}=0.036)$.

In order to assess whether there was any asymmetry in metatarsal bones loading, both feet were compared within each group. The results showed the existence of asymmetry in metatarsal head bones pressure pattern for the left and right feet in the research group (statistical significance based on $\mathrm{chi}^{2}$ independence test). For the left feet, a higher pressure was usually concentrated on $\mathrm{M}_{1}$ and $\mathrm{M}_{2}$ metatarsal bones heads. In contrast, for the right feet, the highest pressure was most often concentrated on the $\mathrm{M}_{3}-\mathrm{M}_{5}$ metatarsal bones heads. The differences in metatarsal bones heads pressure pattern between right and left feet in the control group, however, proved to have no statistical significance.

It was noteworthy that none of the women in the research group had their forefoot areas loaded according to the $\mathrm{M}_{1}>\mathrm{M}_{2}<\mathrm{M}_{3}$ pattern. At the same time, the obtained results proved a reduced loading (statistically significantly lower peak pressure) of both left and right big toes in the research group, compared to the control group (Tab. 1). Those findings are entirely consistent with the research results obtained by Bisiaux and Jacob, which showed that reduced loading of the big toe resulted in a much greater burden placed on the foot second ray $[13,14]$.

For the right foot in the control group, normal medial longitudinal arch (45.65\% of participants) was most frequently observed. A flattened medial longitudinal arch was less common (34.78\% of the women). The most rare were excessive arches (19.57\% of participants). For the right foot in the research group, however, the medial arch was the most flattened (44\% of participants). Proper feet arches were less frequent (only $36 \%$ of participants). The most uncommon were overly-high arches (20\% of the women). Analysis of the differences in these parameters between the research and control groups were not statistically significance (Fig. 3).

Interestingly however, there was a significant difference in the distribution of the frequency of different types of left
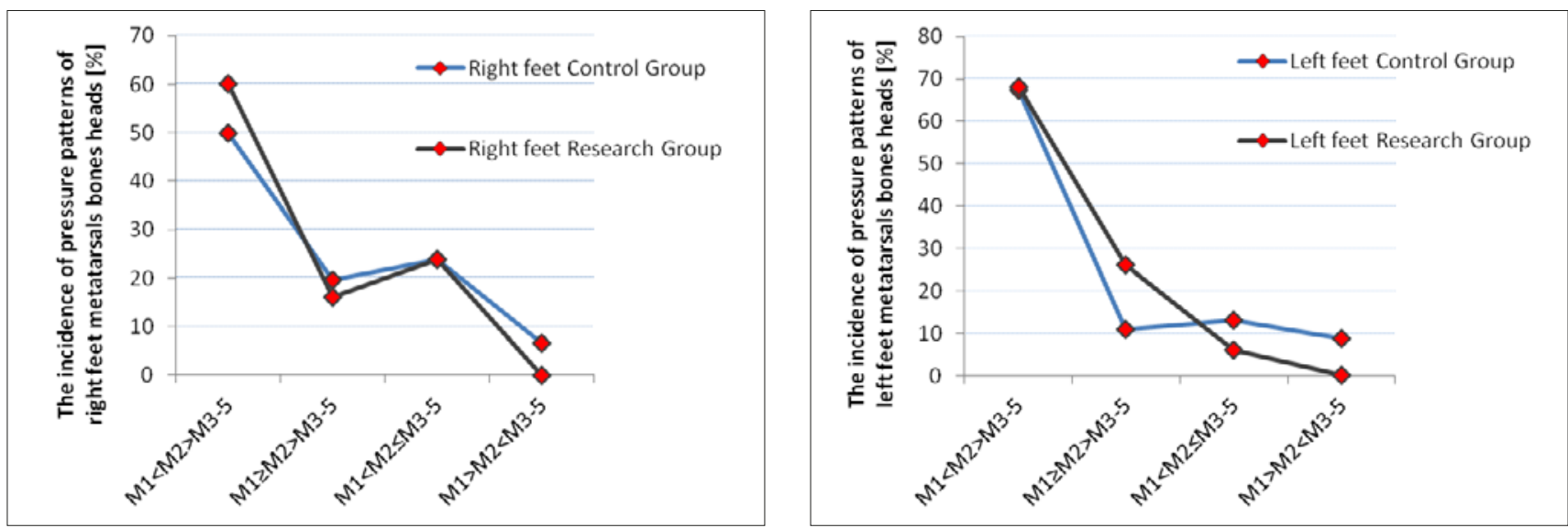

Figure 2. Graphic presentation of the right (a) and the left (b) feet Kantali metatarsal bone pressure distribution pattern (metatarsal bones heads arrangement based on their maximum pressures on the ground). $\mathrm{M}_{1}<\mathrm{M}_{2}>\mathrm{M}_{3-5}-\|$ metatarsal bone head subjected to the most intensive pressure, with lower pressure put on the remaining metatarsal bone heads, $\mathrm{M}_{1} \geq \mathrm{M}_{2}>\mathrm{M}_{3-5}$ - the greatest pressure found on the first metatarsal bone head, or equally, on the first and the second metatarsal bones, with lower pressure between the third and the fifth ones, $M_{1}<M_{2} \leq M_{3-5}$ - the greatest pressure put on metatarsal bones heads between the third and the fifth, or equally distributed between the third and the fifth as well as the second metatarsal bones heads, $M_{1}>M_{2}<M_{3-5}$ - the lowest pressure made on the second metatarsal bones head, with major pressure put on the remaining metatarsal bones heads (functional transverse arch) 

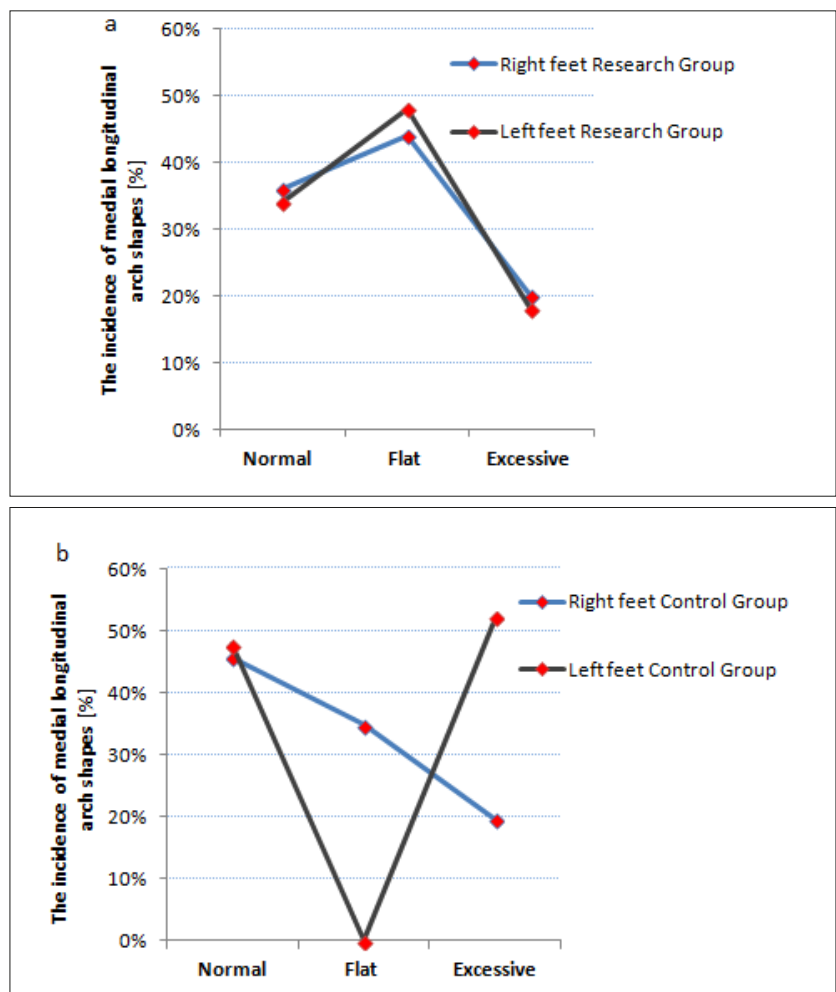

Figure 3. Graphic presentation of the right (a) and the left (b) feet longitudinal arch index according to Cavanagh (relation between full metatarsus (masks 3 and 4) contact surface and a sum of whole foot surface contact area, excluding toes (masks 1 to 7). To calculate Al the following equation was used: $A l=\frac{3+4}{1+2+3+4+5+5+7}$. Three groups have been selected based on the distribution of Al results in the researched population: (1) normal longitudinal medial arch $(13<\mathrm{Al}<24)$; (2) flattened longitudinal medial arch ( $\mathrm{Al} \geq 24)$, (3) excessive longitudinal medial $\operatorname{arch}(\mathrm{Al} \leq 13)$

Table 2. Control and Research Group longitudinal arch index (Al) for both feet (relation between full metatarsus (masks 3 and 4 ) contact surface and a sum of whole foot surface contact area. excluding toes (masks from 1 to 7) [1]. Three groups have been selected based on the distribution of Al results in the researched population: $(\mathrm{N})$ normal longitudinal medial $\operatorname{arch}(13<\mathrm{Al}<24)$; (F) flattened longitudinal medial arch (Al 24$)$, (H) hollow foot (excessive longitudinal arch) $(\mathrm{Al} \leq 13)$

\begin{tabular}{|c|c|c|c|c|c|c|c|}
\hline \multirow{3}{*}{\multicolumn{2}{|c|}{$\begin{array}{l}\text { Arch Index } \\
\text { (Al) for both } \\
\text { feet in }\end{array}$}} & \multicolumn{4}{|c|}{ Side } & \multirow{2}{*}{\multicolumn{2}{|c|}{$\begin{array}{c}\text { Total } \\
\%\end{array}$}} \\
\hline & & \multicolumn{2}{|c|}{ Right } & \multicolumn{2}{|c|}{ Left } & & \\
\hline & & $\begin{array}{l}\text { Number } \\
\text { of persons }\end{array}$ & $\%$ & $\begin{array}{l}\text { Number } \\
\text { of persons }\end{array}$ & $\%$ & $\begin{array}{l}\text { Number } \\
\text { of persons }\end{array}$ & $\%$ \\
\hline \multirow{3}{*}{$\begin{array}{l}\text { Research } \\
\text { Group }\end{array}$} & $\mathrm{N}$ & 18 & 36.00 & 17 & 34.00 & 35 & 35.00 \\
\hline & $\mathrm{F}$ & 22 & 44.00 & 24 & 48.00 & 46 & 46.00 \\
\hline & $\mathrm{H}$ & 10 & 20.00 & 9 & 18.00 & 19 & 19.00 \\
\hline \multicolumn{2}{|l|}{ Total } & 50 & 100.00 & 50 & 100.00 & 100 & 100.00 \\
\hline \multicolumn{8}{|c|}{$\operatorname{chi} 2(2)=.17 ; p=.919$} \\
\hline \multirow{3}{*}{$\begin{array}{l}\text { Control } \\
\text { Group }\end{array}$} & $\mathrm{N}$ & 21 & 45.65 & 22 & 47.83 & 43 & 46.74 \\
\hline & $\mathrm{F}$ & 16 & 34.78 & 0 & .00 & 16 & 17.39 \\
\hline & $\mathrm{H}$ & 9 & 19.57 & 24 & 52.17 & 33 & 35.87 \\
\hline \multicolumn{2}{|l|}{ Total } & 46 & 100.00 & 46 & 100.00 & 92 & 100.00 \\
\hline
\end{tabular}

$\operatorname{chi}^{2}(2)=22.84 ; p=<.001^{*}$

foot arch between the two groups. In the research group, the majority of left feet had a flat medial arch (48\% of participants), $34 \%$ of women had normal medial arch, whereas abnormally high arches were found for $18 \%$ of participants. In the control group, high arches of the left feet were the most common
Table 1. Peak pressure and contact area parameter for both feet in Control and Research Group (CG and RG).P - peak pressure; $C a$ [\% of the whole contact area]-contact area, $R$ - right; $L$ - - left; Numbers $1-10$ - specific areas of foot (masks); T- $t$ Student test result; U M-W- U Mann-Whitney test result; $\mathrm{p}_{\mathrm{t}}-t$ Student test significance level; $\mathrm{p}_{\text {u }}-U$ Mann-Whitney significance level. ${ }^{*} \mathrm{p}<0.05$ - statistically significant differences between the groups. For $P_{\max } 3$ and $P_{\max } 8 t$ Student test and $U$ Mann-Whitney test results were not consistent $\left(p_{t}<0.05 ; p_{u m w}>0.05\right)$. Shapiro-Wilk test was used to determine whether a data-set is well-modeled by a normal distribution or not. Normal distribution of $P \quad 3$ and $P \quad 8$ variables was confirmed and the result of the parametric Student's t-test was considered as the final result

\begin{tabular}{|c|c|c|c|c|c|c|c|c|}
\hline \multirow{2}{*}{$\mathrm{Ca}[\%]$} & \multicolumn{2}{|c|}{ Average } & \multicolumn{2}{|c|}{ Stdev } & \multirow{2}{*}{$T(94)$} & \multirow{2}{*}{$p_{t}$} & \multirow{2}{*}{ U M-W } & \multirow{2}{*}{$\mathbf{p}_{\text {uмw }}$} \\
\hline & CG & RG & CG & RG & & & & \\
\hline CaR1 & 12.72 & 13.31 & 1.15 & 1.23 & -2.42 & $.018 *$ & 790.00 & $.008 *$ \\
\hline CaR2 & 13.74 & 13.70 & 1.12 & 1.45 & .13 & .901 & 1075.00 & .582 \\
\hline CaR3 & 1.38 & 1.75 & .66 & .86 & -2.33 & $.022 *$ & 860.00 & $.033^{*}$ \\
\hline CaR4 & 14.83 & 14.80 & 5.07 & 5.25 & .03 & .973 & 1131.00 & .889 \\
\hline CaR5 & 8.34 & 8.04 & 1.11 & 1.22 & 1.24 & .217 & 982.00 & .218 \\
\hline CaR6 & 9.96 & 10.04 & 1.31 & .95 & -.37 & .711 & 1131.00 & .889 \\
\hline CaR7 & 19.49 & 19.34 & 1.32 & 1.32 & .56 & .577 & 1094.00 & .681 \\
\hline CaR8 & 8.61 & 8.70 & 1.31 & 1.07 & -.37 & .710 & 1141.00 & .947 \\
\hline CaR9 & 5.55 & 5.48 & 1.26 & 1.08 & .30 & .767 & 1111.00 & .775 \\
\hline CaR10 & 5.39 & 4.84 & 1.57 & 1.35 & 1.83 & .070 & 959.00 & .161 \\
\hline CaL1 & 12.72 & 13.36 & 1.39 & 1.25 & -2.36 & $.020 *$ & 827.00 & $.018^{*}$ \\
\hline CaL2 & 13.49 & 13.86 & 1.43 & 1.16 & -1.40 & .165 & 945.00 & .133 \\
\hline $\mathrm{CaL3}$ & 1.70 & 1.74 & 1.00 & .78 & -.21 & .835 & 1083.00 & .623 \\
\hline $\mathrm{CaL} 4$ & 15.88 & 15.25 & 4.34 & 5.16 & .64 & .523 & 1092.00 & .671 \\
\hline CaL5 & 7.97 & 8.10 & 1.11 & 1.09 & -.55 & .583 & 1112.00 & .780 \\
\hline CaL6 & 9.84 & 9.61 & 1.24 & 1.02 & .99 & .324 & 1035.00 & .399 \\
\hline CaL7 & 19.18 & 19.40 & 1.27 & 1.33 & -.81 & .418 & 1072.00 & .567 \\
\hline CaL8 & 8.56 & 8.35 & .96 & 1.15 & .97 & .336 & 1014.00 & .319 \\
\hline CaL9 & 5.42 & 5.47 & 1.19 & 1.02 & -.23 & .817 & 1111.00 & .775 \\
\hline CaL10 & 5.24 & 4.87 & 1.55 & 1.34 & 1.26 & .210 & 982.00 & .218 \\
\hline
\end{tabular}

\section{$\mathbf{P}_{\text {max }}\left[\mathrm{N} / \mathrm{cm}^{2}\right]$}

$\begin{array}{lllllllll}\text { PmaxR1 } & 39.57 & 38.64 & 8.70 & 8.44 & .53 & .595 & 1085.00 & .634\end{array}$

\begin{tabular}{lllllllll}
\hline PmaxR2 & 38.23 & 37.54 & 8.50 & 7.82 & .41 & .679 & 1118.50 & .817
\end{tabular}

\begin{tabular}{lllllllll}
\hline PmaxR3 & 7.76 & 9.75 & 3.18 & 3.75 & -2.78 & $.007 *$ & 814.00 & .014
\end{tabular}

$\begin{array}{lllllllll}\text { PmaxR4 } & 11.03 & 11.87 & 5.95 & 3.23 & -.88 & .384 & 843.50 & .025\end{array}$

$\begin{array}{lllllllll}\text { PmaxR5 } & 33.05 & 31.16 & 16.82 & 14.12 & .60 & .550 & 1107.00 & .752\end{array}$

$\begin{array}{lllllllll}\text { PmaxR6 } & 50.48 & 47.73 & 18.04 & 15.14 & .81 & .419 & 1042.00 & .428\end{array}$

$\begin{array}{lllllllll}\text { PmaxR7 } & 43.87 & 41.28 & 16.55 & 11.31 & .90 & .370 & 1089.00 & .655\end{array}$

\begin{tabular}{lllllllll}
\hline PmaxR8 & 57.09 & 43.52 & 23.38 & 15.74 & 3.36 & $.001 *$ & 770.50 & $.005 *$
\end{tabular}

$\begin{array}{lllllllll}\text { PmaxR9 } & 27.37 & 25.38 & 10.34 & 9.99 & .96 & .341 & 1010.00 & .304\end{array}$

$\begin{array}{lllllllll}\text { PmaxR10 } & 17.24 & 17.11 & 6.12 & 6.98 & .10 & .923 & 1110.50 & .772\end{array}$

$\begin{array}{lllllllll}\text { PmaxL1 } & 41.08 & 38.65 & 9.80 & 8.71 & 1.29 & .201 & 998.50 & .266\end{array}$

$\begin{array}{lllllllll}\text { PmaxL2 } & 39.08 & 37.44 & 9.35 & 8.21 & .92 & .362 & 1063.50 & .526\end{array}$

$\begin{array}{lllllllll}\text { PmaxL3 } & 8.32 & 9.56 & 3.44 & 3.53 & -1.74 & .085 & 947.00 & .136\end{array}$

\begin{tabular}{lllllllll} 
PmaxL4 & 10.95 & 12.18 & 4.07 & 3.81 & -1.52 & .131 & 890.50 & .057 \\
\hline
\end{tabular}

\begin{tabular}{ccccccccc}
\hline PmaxL5 & 33.60 & 28.54 & 16.55 & 14.42 & 1.60 & .113 & 894.00 & .060 \\
\hline PmaxL6 & 51.85 & 51.37 & 17.99 & 19.08 & .13 & .900 & 1121.00 & .832 \\
\hline PmaxL7 & 43.45 & 45.77 & 12.75 & 16.14 & -.78 & .439 & 1100.50 & .717 \\
\hline PmaxL8 & $\mathbf{5 1 . 1 8}$ & $\mathbf{4 1 . 6 3}$ & $\mathbf{1 8 . 9 9}$ & $\mathbf{2 1 . 4 0}$ & $\mathbf{2 . 3 0}$ & $\mathbf{. 0 2 3} *$ & $\mathbf{8 0 8 . 5 0}$ & $\mathbf{. 0 1 2}$ \\
\hline PmaxL9 & 28.99 & 25.58 & 10.39 & 10.14 & 1.63 & .107 & 907.50 & .075 \\
\hline PmaxL10 & 18.18 & 16.19 & 7.23 & 7.04 & 1.37 & .175 & 946.00 & .135
\end{tabular}


(52.17\% of participants). The occurrence of normal arches was less frequent (47.83\% of women). It is important that none of women in the control group exhibited a flattened left foot medial arch (Fig. 3).

In order to assess whether there was any asymmetry in medial arch shapes, both feet were compared within each group. The $\mathrm{chi}^{2}$ independence test proved the statistical significance of differences observed between the left foot medial arch in the control group $(p<0.001)$ (Tab. 2). Comparative analysis of both feet in the research group showed a similarity in their arches indexes, which was confirmed by a lack of significant differences in the chi ${ }^{2}$ independence test $(p=0.919)$ (Tab. 2). The results obtained indicate that in the non-jogging group the physiological asymmetry in the shape of the medial arch was more likely to appear, with the left feet exhibiting a higher tendency to a hollow structure, and the right feet having a tendency to a proper medial arch shape.

\section{DISCUSSION}

Research by Kantali proved that the $\mathrm{M}_{2}$ and $\mathrm{M}_{3}$ undergo the highest pressure, compared to the remaining metatarsal bones, which challenges the transverse arch theory [15]. According to Kantali, the central part of the foot is predominantly subjected to the greatest loads, as confirmed in $63.3 \%$ of the participants in his research [11]. The current study affirms Kantali's observations. In the majority of the presented research population, the central part of the metatarsal bones is subjected to the greatest loads. The most frequent metatarsal bone heads pressure pattern in both groups was $\mathrm{M}_{1}<\mathrm{M}_{2}>\mathrm{M}_{3}-{ }_{5}$ and was observed for $60 \%$ of the right and $68 \%$ of the left feet in the research group.

It is widely accepted that the metatarsal heads constitute an arch also in the anterior-posterior plane, generally known as Le Lie'vre's metatarsal parabola in which the second metatarsal bone is relatively longer in comparison to remaining metatarsal bones [16], and is deeply wedged in-between the first and third cuneiforms.This makes the second meatarsal bone relatively fixed, with only dorsiflexion and plantarflexion movement being possible, in contrast to the other metatarsal bones which can also perform rotational movements. For this reason the second metatarsal bone is considered to be the central part of the metatarsus. The arched structure of metatarsal bones is supposed to make them - instead of moving directly down during the plantar flexion - bend outward with respect to the axis $\left(\mathrm{M}_{2}\right)$ increasing transverse arch [17]. Seen from this perspective, abnormalities of the relative lengths of the metatarsals and subsequent non-harmonious Lie'vre's metatarsal parabola could cause changes in transverse arch forming. This could subsequently lead to increased second metatarsal loading, which should be addressed in future research.

Kantali observed the existence of a transverse arch in only $1.9 \%$ of the participants of his study [11]. In the presented study, none of the subjects in research group had a transverse arch, whereas in the control group it was been noted for as little as $8.7 \%$ of the left feet and $6.52 \%$ of the right feet. This result supports the theory that there is no transverse arch, which and indicates a higher loading of $\mathrm{M} 2$ in the for research groupresearch group, compared with the control group. The latter complies with the results obtained by Weist and Bisiaux who noted increased loading of second metatarsal head after a fatiguing run $[13,18]$. This is an important observation, because according to Jacob, increased pressure under the head of the second metatarsal resulted in an elevated bending moment of $\mathrm{M}_{2}$, which predispose to its stress fractures [14].

Interestingly, together with the higher loading of $\mathrm{M}_{2}$ in the female joggers group, the presented research results prove a reduced loading (statistically significantly lower peak pressure) of both left and right big toe in research group, compared to the control group (Tab. 1). These results also comply with those of Bisiaux and Jacob, that the lack of big toe bearing function can result in shift of loading to the central forefoot $[13,14]$. The diminished role of the big toe in load transfer is considered to be a result of the foot and ankle joints mobility [19], or altered activity of the muscles responsible for big toe surface contact pressure [13]. To find the exact cause for the reduced big toe loading observed in the current study, further research including kinematic and electromyographic measurements would be required.

In his study, Kantali observed a maximum pressure pattern located in the metatarsal medial part in only $17.8 \%$ of participants [11]. A similar result was obtained in the current study for the right feet in the research group $-16 \%$ of participants. The left feet of the same group (research group) showed a considerably higher value $-26 \%$. According to Kantali, lateral metatarsal pressure pattern affects $17 \%$ of participants [11]. In the presented study, such a pattern was observed in the case of the left feet for $6 \%$, and for the right feet for $24 \%$ of the research group.

Interestingly, the results of the current study demonstrate the existence of asymmetry in metatarsal head bones pressure pattern for the left and right feet in the research group (statistical significance based on $\mathrm{chi}^{2}$ independence test). For the left feet, a higher pressure usually concentrated on the $\mathrm{M}_{1}$ and $\mathrm{M}_{2}$ metatarsal bones heads. In contrast, for the right feet, the highest pressure was most often concentrated on $M_{3}-M_{5}$ metatarsal bones heads. Further research is needed to find the explanation for this observation. The differences in metatarsal bones heads pressure pattern between right and left feet in the control group, however, proved to have no statistical significance.

A study by McPoil and Corwall showed that medial arch collapse is greater in running than walking [20], which they deemed reasonable considering loading and triceps surae muscle activity are greater in running. Interestingly, the results of the current research seem to indicate that repeated jogging cycles could result in permanent medial arch flattening. Women from the research group, more often than from the control group, displayed flat medial arch in the walk support phase - for the research group, $44 \%$ of the right and $48 \%$ of the left feet, whereas for the control group, $34.78 \%$ of the right and $0 \%$ of the left feet (statistically relevant differences for the left feet only). This indicates that there are changes in the biomechanics of a female runner's feet that lead to medial foot arch flattening. The reason for medial arch collapse among female runners may be its gradual lengthening, caused by decrease in its tension over time with constant or repetitive force [21]. It could be also related to malfunction of the structures responsible for the maintenance of the shape of the medial longitudinal arch. Moreover, it may also be caused by the increased activity of the triceps surae during mid-stance, when it assists in medial arch depression increasing ankle plantarflexion. Finally, a 
change in the function of muscles which actively control rotation of subtalar and other joints of the arch could also be a contributing factor [22]. An exact reason for the tendency to medial arch flattening among female joggers cannot be found based on the results of this presented study, and should be sought for in future research. Moreover, analysis of the arch symmetry showed its presence in the research group, while the control group proved to have statistically significant differences in the structure of the arches in both feet, with the female joggrs left side having a higher tendency for higharched foot on the differences in the right and left feet arch shapes.

\section{CONCLUSIONS}

The study demonstrates the influence of jogging exercise on female joggers biomechanical behaviour of the foot. Significant differences between analyzed indices between the research and the control groups have been observed, most importantly: differences in longitudinal, medial and transversal arch structure and changes in bilateral symmetry of loading. The results show that the transversal arch was scarcely present in the control group population, and did not occur at all among the female joggers. The study shows a higher frequency of medial longitudinal foot arch flattening among female runners, with a great deal of consistency between both feet, whereas the results for the control group showed asymmetrical medial arch shapes with right foot propensity to normal arch shape, and left foot tendency to excessive arch.

\section{REFERENCES}

1. Kapandji IA. The physiology of the joints: annotated diagrams of the mechanics of the human joints. Vol. 2. Lower Limb. Edinburgh, Churchill Livingstone, 1970.p.196-219.

2. Daentzer D, Wülker N, Zimmermann U. Observations concerning the transverse metatarsal arch. J Foot Ankle Surg. 1997; 3(1): 15-20.

3. Franco AH. Pes cavus and pes planus. Analyses and treatment. Phys Ther. 1987; 67(5): 688-694.
4. Ker RF, Bennett MB, Bibby SR, Kester RC, Alexander RM. The spring in the arch of the human foot. Nature. 1987; 325: 147-149.

5. Saibene F, Minetti AE. Biomechanical and physiological aspects of legged locomotion in humans. Europ J App Physiol. 2003; 88: 297-316.

6. Barr KP, Harrast MA. Evidence-Based Treatment of Foot and Ankle Injuries in Runners. Phys Med Rehabil Clin N Am. 2005; 16: 779-799.

7. Taunton JE, Ryan MB, Clement DB, McKenzie DC, Lloyd-Smith DR, Zumbo DB. A retrospective case-control analysis of 2002 running injuries. BJSM. 2002; 36(2): 95-101.

8. Ferber R, Davis IM, Williams DS. Gender differences in lower extremity mechanics during running. Clin Biomech. 2003; 18(4): 350-357.

9. Bus SA, de Lange A. A comparison of 1-step, 2-step, and 3-step protocols for obtaining barefoot plantar pressure data in the diabetic neuropathic foot. Clin Biomech. 2005; 20: 892- 899.

10. Cavanagh PR, Rodgers MM, Iboshi A. Pressure distribution under symptom-free feet during barefoot standing. Foot Ankle. 1987a; 7(5): 262-276.

11. Kantali U, Yetkin H, Simsek A, Ozturk AM, Esen E, Besli K. Pressure distribution patterns under the metatarsal heads in healthy individuals. Acta Orthop et Traumatol Turcica. 2008; 42(1): 26-30.

12. Cavanagh PR, Rodgers MM. The arch index: a useful measure from footprints. J Biomech. 1987b; 20(5): 547-551.

13. Bisiaux M, Moretto $P$. The effects of fatigue on plantar pressure distribution in walking. Gait and Post. 2008; 28: 693-698.

14. Jacob HAC. Forces acting in the forefoot during normal gait-an estimate. Clin Biomech. 2001; 16: 783-792.

15. Kantali U, Yetkin H, Bolukbasi S. Evaluation of the transverse metatarsal arch of the foot with gait analysis. Arch Orthop Trauma Surg. 2003; 123: 148-150.

16. Simonsen O, Vuust M, Understrup B, Højbjerre M et. al. The transverse forefoot arch demonstrated by a novel X-ray projection. Foot and Ankle Surgery 2009; 15: 7-13.

17. Ombregt L, Bisschop P, ter Veer HJ. A System of Orthopaedic Medicine. 2nd ed. Churchill Livingstone, 2003.p.1161-1165.

18. Weist R, Eils E, Rosenbaum D. The influence of muscle fatigue on electromyogram and plantar pressure patterns as an explanation for the incidence of metatarsal stress fractures. Amer J Sport Med. 2004; 32(8): 1893-1898.

19. Morag E, Cavanagh PR. Structural and functional predictors of regional peak pressures under the foot during walking. J Biomech. 1999; 32: 359-370.

20. McPoil T, Cornwall M. Prediction of dynamic foot posture during running using the longitudinal arch angle. JAPMA. 2007; 97(2): 102107.

21. Whiting W, Zernicke R. Biomechanics of musculoskeletal injury. 2nd ed. United States of America, 2008.p.90.

22. Cheung JTM, Zhang M, An KN. Effect of Achilles tendon loading on plantar fascia tension in the standing foot. Clin Biomech. 2006; 21: 194-203. 